ISSN 2338-1523

E-ISSN 2541-576X

Volume 6 No. 2

Desember 2018

\title{
PERANCANGAN SISTEM PAKAR MENDIAGNOSA PENYAKIT KULIT PADA ANAK DENGAN MENGGUNAKAN METODE BACKWARD CHAINING
}

\author{
Nico Alvio Maiyedra \\ email: nicoalvio34@gmail.com \\ Program Studi Sistem Informasi, STMIK GICI
}

\begin{abstract}
Abstrak
Sistem pakar (expert system) pada umumnya adalah mencoba mengadopsi sistem pengetahuan manusia ke dalam komputer, sehingga komputer dapat menyelesaikan masalah seperti yang dilakukan oleh para ahli. Atau dengan kata lain, sistem pakar adalah sistem yang dirancang dan diimplementasikan dengan bantuan bahasa pemrograman khusus untuk dapat menyelesaikan masalah seperti yang dilakukan oleh para ahli. Dalam hal ini saya mencoba menerapkan sistem pakar untuk mendiagnosa penyakit kulit untuk anak-anak dari gejala dan penyebab penyakit kulit untuk anak-anak. Tujuan penulisan ini adalah membangun sistem berbasis pengetahuan tentang kanker otak dengan menggunakan metode backward chaining yang akan ditampilkan dalam bentuk website dengan menggunakan pemrograman PHP dan database MySQL
\end{abstract}

\begin{abstract}
Expert systems (expert systems) in general is trying to adopt a system of human knowledge into a computer, so the computer can resolve the problem as was done by the experts. Or in other words, the expert system is a system designed and implemented with the help of a specific programming language to be able to resolve the problem as done by experts. In this case I tried to implement an expert system to diagnose skin diseases for children from the symptoms and the causes of skin diseases for children. The purpose of this paper is to build a knowledge-based system on brain cancer using backward chaining method that will be displayed in the form of a website using PHP programming and MySQL database.
\end{abstract}

\section{Keyword $\quad$ : Expert System, skin diseases for children, Backward Chaining}

\section{PENDAHULUAN}

Latar Belakang Masalah

Kesehatan merupakan hal yang paling berharga bagi manusia, karena siapa saja dapat mengalami gangguan kesehatan. Anak sangat rentan dengan berbagai kuman penyakit dan kurangnya kepekaan terhadap gejala suatu penyakit merupakan ketakutan tersendiri bagi orang tua. Orang tua merupakan orang awam yang terkadang kurang memahami kesehatan. Apabila terjadi gangguan kesehatan dengan anaknya maka mereka lebih mempercayakannya kepada seorang pakar atau dokter ahli yang sudah mengetahui lebih banyak tentang kesehatan, tanpa memperdulikan apakah gangguan tersebut masih dalam tingkat rendah atau kronis. Penyakit kulit sering menyerang anak-anak, kulit merupakan organ terluar dan merupakan organ perlindungan
JURSIMA

Jurnal Sistem Informasi dan Manajemen https://ejournal.stmikgici.ac.id//

STMIK GICI 
pertama pada anak sehingga, jika terjadi sesuatu pada anak organ yang lebih dahulu terkena adalah kulit. Namun dengan kemudahan dengan adanya para pakar atau dokter ahli, terkadang dapat pula kelemahannya seperti jam kerja terbatas dan banyaknya pasien sehingga harus menunggu antrian. Dalam hal ini orang tua selaku pemakai lebih membutuhkan seorang pakar yang bisa memudahkan dalam mendiagnosa penyakit lebih dini agar dapat melakukan pencegahan lebih awal yang sekiranya membutuhkan waktu jika berkonsultasi dengan dokter ahli. Oleh karena itu dibutuhkan suatu alat bantu yang dapat mendiagnosa penyakit anak berupa sistem pakar.

Sistem pakar merupakan salah satu cabang dari kecerdasan buatan yang mempelajari bagaimana "mengadopsi" cara seorang berpikir dan bernalar dalam dalam menyelesaikan suatu permasalahan dan embuat suatu keputusan maupun mengambil suatu tujuan dari sejumlah fakta yang ada. Kecerdasan buatan atau Artificial Intelligence memiliki beberapa cabang ilmu yang lebih spesifik, diantaranya adalah sistem pakar. Dasar dari sistem pakar adalah bagaimana memindahkan pengetahuan yang dimiliki oleh seorang pakar kedalam komputer, dan bagaimana membuat keputusan atau mengambil kesimpulan berdasarkan pengetahuan itu.

Penjabaran di atas mendorong penulis untuk membuat "Perancangan Aplikasi Sistem Pakar Untuk Mendiagnosa Penyakit Kulit Pada Anak Dengan Menggunakan Metode Backward
Chaining". Perancangan sistem pakar ini akan dibuat berbasis web melalui media PHP dengan basis data menggunakan $M y S Q L$ yang terdapa dalam paket XAMPP.

\section{Maksud dan Tujuan Penelitian}

Tujuan perancangan aplikasi sistem pakar diagnosa penyakit kulit pada anak ini yaitu:

1. Memahami parameter-parameter yang digunakan didalam sistem.

2. Menganalisa sistem yang akan digunakan di dalam aplikasi sehingga aplikasi bisa bersifat fleksibel dan tidak membingungkan pengguna.

3. Merancang sebuah aplikasi yang dapat digunakan dan dipahami oleh user.

4. Membangun aplikasi dengan baik agar bisa dipakai oleh user dan dapat di-update oleh admin dengan menggunakan bahasa pemrograman $P H P$ dan database $M y S Q L$

5. Menguji aplikasi yang dirancang dan dibangun agar bisa dianalisa kembali jika masih ada kekurangan atau masih ada yang perlu dirombak.

6. Aplikasi dapat dipakai dan digunakan oleh para orang tua.

Perumusan Masalah

Adapun perumusan masalah dari penelitian ini adalah sebagai berikut:

1. Bagaimana aplikasi sistem pakar kedokteran yang dirancang dapat mendiagnosa penyakit kulit pada anak?

2. Bagaimana dengan diterapkannya aplikasi, mampu memberikan informasi mengenai gejala penyakit kulit
JURSIMA

Jurnal Sistem Informasi dan Manajemen https://ejournal.stmikgici.ac.id/

STMIK GICI 
yang terjadi pada anak tersebut dengan cepat?

3. Bagaimana sistem yang dirancang dengan menggunakan bahasa pemprograman $P H P$ ini dapat tersimpan dan berkoneksi dengan baik kedalam basis data dengan menggunakan $M y S Q L$.

\section{LANDASAN TEORI}

\section{Rekayasa Perangkat Lunak}

Rekayasa perangkat lunak (software engenering) merupakan pembangunan dengan menggunakan prinsip atau konsep rekayasa dengan tujuan menghasilkan perangkat lunak yang bernilai ekonomi yang dipercaya dan bekerja secara efisien menggunakan mesin. Perangkat lunak banyak dibuat dan pada akhirnya sering tidak digunakan karena tidak memenuhi kebutuhan pelanggan atau bahkan karena masalah non-teknis seperti keengganan pemakai perangkat lunak (user) untuk mengubah cara kerja dari manual ke otomatis atau ketidakmampuan user mengguanakan komputer. Oleh karena itu, rekayasa perangkat lunak dibutuhkan agar perangkat lunak yang dibuat tidak hanya menjadi perangkat lunak yang tidak terpakai (Rosa A.S-M.Shalahuddin, 2011).

\section{Kecerdasan Buatan}

Kecerdasan buatan berasal dari bahasa inggris "Artificial Intelligence" atau disingkat AI, yaitu intelligence adalah kata sifat yang berarti cerdas, sedangkan artificial artinya buatan. Kecerdasan buatan yang dimaksud disini merujuk kepada mesin yang mampu berfikir, menimbang tindakan yang akan diambil, dan mampu mengambil keputusan seperti yang dilakukan oleh manusia. Berikut adalah beberapa definisi kecerdasan buatan yang telah didefinisikan oleh beberapa ahli (Dr. Vincent Suhartono, 2011):

\section{Pengertian Sistem Pakar}

Menurut Muhammad Arhami (2005:9) system pakar merupakan paket perangkat lunak atau paket pemprograman komputer yang ditujukan sebagai penyedia nasehat dan sarana bantu dalam memecahkan masalah dalam bidang-bidang spesialis tertentu seperti sains, kedokteran, pendidikan dan sebagainya. Istilah sistem pakar berasal dari istilah knowledge-based expert system. Istilah ini muncul karena untuk memecahkan masalah, sistem pakar menggunakan pengetahuan seorang pakar yang dimasukkan ke dalam komputer.

Manfaat dan Kekurangan Sistem Pakar

Sutojo dkk (2011) juga mengungkapkan "Sistem pakar menjadi sangat populer karena sangat banyak kemampuan dan manfaat yang diberikanya", yaitu :

1. Meningkatkan produktivitas, karena sistem pakar dapat bekerja lebih cepat daripada manusia.

2. Membuat seorang yang awan bekerja seperti layaknya seorang pakar dengan sistem yang dibuat sedemikian rupa.

3. Meningkatkan kualitas dengan mamberi nasehat yang konsisten dan mengurangi kesalahan.

4. Mampu menangkap pengetahuan dan kemampuan seorang pakar.

5. Dapat beroperasi di lingkunag yang berbahaya.
JURSIMA

Jurnal Sistem Informasi dan Manajemen https://ejournal.stmikgici.ac.id// STMIK GICI 
6. Memudahkan akses pengetahuan seorang pakar.

7. Andal, karena Sistem Pakar tidak pernah menjadi bosan, kelelahan dan sakit.

8. Meningkatkan kemampuan untuk menyelesaikan masalah karena sistem pakar mengambil sumber pengetahuan dari banyak pakar.

Selain manfaat, ada juga beberapa kekurangan yang ada pada sistem pakar, diantaranya :

1. Biaya yang sangat mahal untuk membuat dan memeliharanya.

2. Sulit dikembangkan karena keterbatasan keahlian dan ketersediaan pakar.

3. Sistem pakar tidak $100 \%$ bernilai benar.

\section{Ciri dan Area Permasalahan Sistem Pakar}

Ciri-ciri dari sistem pakar (Sutojo dkk : 2001), adalah sebagai berikut :

1. Terbatas pada domain keahlian tertentu.

2. Dapat menjelaskan alasan-alasan dengan cara yang dapat dipahami.

3. Bekerja berdasrkan kaidah atau rule tertentu.

4. Mudah dimodifikasi.

5. Keluarannya bersifat anjuran.

6. Sistem pakar mengaktifkan kaidah secara searah yang sesuai, dituntun oleh dialog dengan pengguna.

Biasanya aplikasi sistem pakar menyentuh pada beberapa area permasalahan, yaitu :

1. Interpretasi, menghasilkan deskripsi stuasi berdasarkan datadata masukan.

2. Prediksi, memperkirakan akibat yang mungkin terjadi dari situasi yang ada.
3. Diagnosis, menyimpulkan suatu keadaan yang berdasarkan gejalagejala yang diberikan (Symptoms).

4. Desain, melakukan perancangan berdasarkan kendala-kendala yang diberikan.

5. Planning, merencanakan tindakantindakan yang akan dilakukan.

6. Monitoring, membandingkan hasil pengamatan dengan proses perencanaan.

7. Debugging, menuntun penyelesaian dari suatu kesalahan sistem.

8. Reparasi, melaksanakan rencana perbaikan.

9. Intruction, melakukan intruksi untuk diagnosis, debugging dan perbaikan kinerja.

10. Control, melakukan pengawasan terhadap interpretasi, diagnosis, debugging, monitoring dan perbaikan tingkah laku sistem.

\section{Konsep Dasar Sistem Pakar}

Dari beberapa penjelasan mengenai sistem pakar ada beberapa konsep dasar sistem pakar (Sutojo dkk, 2011), diantaranya :

1. Kepakaran (Expertise), adalah merupakan suatu pengetahuan yang diperoleh dari pelatihan, membaca dan pengalaman.

2. Pakar (Expert), adalah seorang yang mempunyai pengetahuan, pengalaman dan metode khusus serta mampu menerapkanya untuk memecahkan suatu masalah atau memberi nasehat.

3. Pemindahan Kepakaran (Transferring Expertise), adalah memindahkan kepakaran dari seorang pakar ke dalam komputer, kemudian ditransfer kepada orang lain yang bukan pakar.
JURSIMA

Jurnal Sistem Informasi dan Manajemen $\underline{\text { https://ejournal.stmikgici.ac.id/ }}$ STMIK GICI 
2.Inferensi (Inferencing), adalah sebuah prosedur (program) yang mempunyai kemampuan dalam penalaran.

3.Aturan-aturan (Rule), yaitu pengetahuan disimpan dalam bantuk aturan-aturan sebagai prosedurprosedur pemecahan masalah.

4. Kemampuan Menjelaskan (Explanation Capability), yaitu kemampuan untuk menjelaskan saran atau rekomendasi yang diberikanya.

\section{Komponen Sistem Pakar}

Ada dua bagian penting dari sistem pakar, yaitu lingkungan pengembangan dan lingkungan konsultasi. Lingkungan pengembangan digunakan oleh pembuat sistem pakar untuk membangun komponenkomponenya dan memperkenalkan pengetahuanya ke dalam knoledge base (basis pengetahuan). Lingkungan kosultasi digunakan oleh pengguna untuk berkonsultasi sehingga pengguna mendapatkan pengetahuan dan nasihat dari sistem pakar layaknya berkonsultasi dengan seorang pakar.

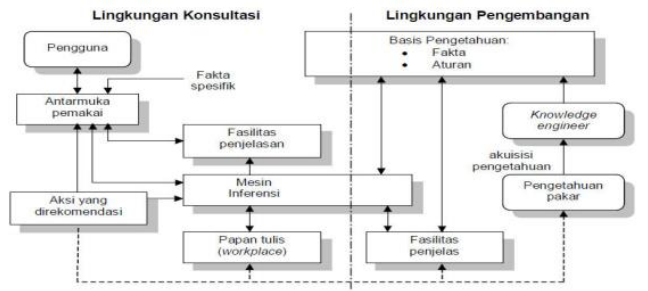

Sumber : Sutojo dkk (2011)

Gambar 2.3 Komponen-Komponen Sistem Pakar

Keterangan :

1. Akuisisi Penetahuan, "Memasukkan pengetahuan dari seorang pakar dengan cara merekayasa pengetahuan dan meletakkannya dalam basis pengetahuan".
2. Basis Pengetahuan (Knowledge Based), "Yaitu mengandung pengetahuan yg diperlukan untuk memahami, memformulasikan dan menyelesaikan masalah".

3. Mesin Inferensi (Inference Enginer), "Program yang berfungsi untuk memandu proses penalaran terhadap suatu kondisi berdasarkan basis pengetahuan yang ada, memanipulasi dan mengarahkan aturan, model dan fakta yang disimpan".

4. Daerah Kerja (Blackboard), "Merekam hasil sementara yang dijadikan sebagai keputusan dan menjelaskan masalah yang sedang terjadi”.

5. Antarmuka Pengguna (User Interface), "Media komunikasi antara pengguna dengan sistem pakar".

6. Subsistem Penjelasan (Explannation Subsystem), "Memberikan penjelasan pada pengguna, bagaiman kesimpulan dapat diambil".

7. Sistem Perbaikan Pengetahuan (Knowledge Refining System), "Yaitu memampuan untuk memperbaiki pengetahuan dari seorang pakar. Belajar dari masa lalu, kemudian memperbaiki dan menggunakannya untuk masa mendatang".

8. Pengguna (User), "Pada Umumnya pengguna sistem pakar bukanlah seorang pakar yang membutuhkan solusi, saran atau pelatihan dari berbagai permasalahan yang ada".

Tim Pengembang Sistem Pakar Sutojo dkk (2011) juga merumuskan tim dalam pengembangan sistem pakar, "Beberapa tim dalam pengembangan sistem pakar, yaitu
JURSIMA

Jurnal Sistem Informasi dan Manajemen https://ejournal.stmikgici.ac.id/

STMIK GICI 
domain expert, knowledge enginer, project manager dan end-user".

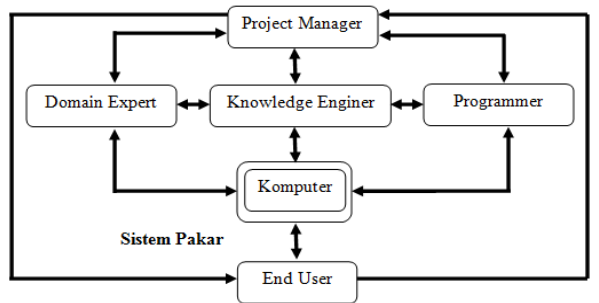

Sumber : Sutojo dkk (2011)

Gambar 2.4 Tim Pengembangan

\section{Sistem Pakar}

Keterangan :

1.Domain expert (pakar) adalah kemampuan dan pengetahuan seorang pakar untuk menyelesaikan masalah terbatas pada keahlianya.

2. Knowledge (prekayasa pengetahuan) adalah orang yang mampu mendesain, membangun dan menguji sebuah sistem pakar.

3. Progremer adalah orang yang membuat sistem pakar, mengode domain pengetahuan agar dapat dimengerti oleh komputer.

4. Project manager adalah pemimpin dalam pengembangan sistem pakar.

5. End-user adalah orang yang menggunakan sistem pakar dari hasil pengembangan sistem pakar.

2.3 Metode Inferensi

Komponen ini mengandung mekanisme pola pikir dan penalaran yang digunakan oleh pakar dalam menyelesaikan suatu masalah. Metode inferensi adalah program komputer yang dapat memberikan metedologi untuk penalaran tentang informasi yang ada dalam basis pengetahuan dan dalam workplace, dan untuk memformulasikan kesimpulan (Sutojo, dkk : 2011).

Terdapat dua pendekatan untuk mengontrol inferensi dalam perancangan sistem pakar ini, yaitu pelacakan ke belakang (Backward chaining) dan faktor kepastian (Certainty Factor).

\section{Runut Mundur (Backward Chaining)}

Pelacakan ke belakang adalah pendekatan yang dimotori oleh tujuan (goaldriven). Dalam pendekatan ini pelacakan dimulai dari tujuan, selanjutnya dicari aturan yang memiliki tujuan tersebut untuk kesimpulannya. Selanjutnya proses pelacakan menggunakan premis untuk aturan tersebut sebagai tujuan baru dan mencari aturan lain dengan tujuan baru sebagai kesimpulannya. Proses berlanjut sampai semua kemungkinan ditemukan.

Backward Chaining adalah inferensi yang bekerja mundur kearah kondisi awal. Proses diawali dengan Goal (yang berada dibagian THEN dari rule IFTHEN), kemudian pencarian mulai dijalankan untuk mencocokan apakah fakta-fakta yang ada cocok dengan premis-premis di bagian IF. Jika cocok, rule diekskusi, kemudian hipotesis dibagian THEN ditempatkan dibasis data sebagai fakta baru. Jika tidak cocok, simpan premis di bagian IF ke dalam stack sebagai subGoal. Proses berakhir jika Goal ditemukan atau tidak ada rule yang bisa membuktikan kebenaran dari subGoal atau Goal (Sutojo, dkk, 2011).

\section{Runut Maju (Forward Chaining)}

Forward Chaining adalah teknik pencarian yang dimulai dengan fakta yang diketahui, kemudian mencocokkan fakta fakta tersebut dengan bagian IF dari rules IF-THEN. Bila ada sebuah rule dieksekusi, maka sebuah fakta baru (bagian THEN) ditambahkan kedalam database(Sutojo, dkk , 2011). Setiap kali pencocokan,
JURSIMA

Jurnal Sistem Informasi dan Manajemen https://ejournal.stmikgici.ac.id/

STMIK GICI 
dimulai dari rule teratas. Setiap rule hanya boleh diesekusi sekali saja. Metode Pencarian yang digunakan adalah Depth-First Search (DFS), Breadth-First Search (BFS) atau Best First Search.

\section{Unifield Model Language (UML)} UML (Unifield Modeling Language) adalah standar bahasa yang banyak digunakan di dunia industri untuk mendefinisikan requirement, membuat analisis \& desain, serta menggambarkan arsitektur dalam pemrograman berorientasi objek (M. Shalahuddin, 2013).

\section{Konsep Dasar UML (Unifield Model Language)}

Untuk menguasai $U M L$, sebenarnya cukup dua hal yang perlu diperhatikan, antara lain (M. Shalahuddin dkk, 2013):

1. Menguasai pembuatan diagram UML (Unifield Modeling Language).

2. Menguasai langkah-langkah dalan analisa dan pengembangan UML (Unifield Modeling Language).

Berikut ini adalah beberapa jenis diagram yang digunakan dalam pembuatan diagram UML (Unifield Modeling Language):

1. Use Case Diagram.

2. Class Diagram.

3. Sequencece Diagram.

4. State Chart Diagram.

5. Collaboration Diagram.

6. Deployment Diagram.

7. Activity Diagram.

Database

\section{Definisi Database}

Database adalah sekumpulan file data yang saling berhubungan dan diorganisasikan sedemikian rupa sehingga memudahkan untuk mendapat dan memproses data. Lingkungan sistem database menekankan data yang tidak tergantung (independent data) pada fakta dasar (mentah) yang terpisah (Andi, 2006). Sistem basis data adalah sistem terkomputerisasi yang tujuan utamanya adalah memelihara data yang sudah diolah atau informasi dan membuat informasi tersedia saat dibutuhkan. Pada intinya basis data adalah media untuk menyimpan data agar dapat diakses dengan mudah dan cepat (Rosa A.S-M. Shallahudin, 2011).

\section{HASIL DAN PEMBAHASAN}

Analisa Data

Tahap analisa dari sistem pakar untuk diagnosa penyakit penyakit kulit pada anak ini di tujukan untuk melakukan evaluasi menyeluruh terhadap kinerja sistem terhadap lingkungan yang ditujunya. Apakah dengan perancangan sistem ini user akan terbantu dengan permasalahan yang dihadapinya, atau apakah user merasa lebih bingung tentang informasi yang diberikan.

Tujuan dari analisis sistem ini adalah mengetahui apakah sistem yang telah dibuat mampu menggantikan para pakar dan bagaimana tingkat keefisienan user dari segi waktu dan biaya daripada harus langsung berhadapan dengan seorang pakar. Bagaimana sistem dapat menggantikan atau mengisi kelemahan yang sering 
ISSN 2338-1523

E-ISSN 2541-576X

Volume 6 No. 2

Desember 2018

terjadi akibat dari kesalahan pakar, seperti: meningkatkan output dan produktivitas, menjadikan pengetahuan dan nasihat lebih mudah didapat, menyimpan kemampuan keahlian pakar, memberikan respons (jawaban) yang cepat, sehingga sistem ini dapat menanggulangi itu semua, jadi tingkat keakuratan akan lebih bisa ditingkatkan lagi.

Tabel 4.1 Penyakit penyakit kulit pada anak

\begin{tabular}{|c|c|}
\hline $\begin{array}{c}\text { Kode } \\
\text { penyakit }\end{array}$ & Nama penyakit \\
\hline B001 & $\begin{array}{l}\text { Roseola } \\
\text { infantum }\end{array}$ \\
\hline B002 & $\begin{array}{ll}\begin{array}{l}\text { Parvoviru } \\
\text { (sindrom }\end{array} & \begin{array}{l}\text { B19 } \\
\text { pipi }\end{array} \\
\text { merah) } & \\
\end{array}$ \\
\hline B003 & $\begin{array}{l}\text { Impetigo } \\
\text { krustosa(cacar } \\
\text { madu) }\end{array}$ \\
\hline B004 & $\begin{array}{l}\text { Impetigo bulosa } \\
\text { (cacar api) }\end{array}$ \\
\hline B005 & Cacar air \\
\hline B006 & $\begin{array}{l}\text { Rubeola } \\
\text { (campak } 9 \text { hari) }\end{array}$ \\
\hline B007 & $\begin{array}{l}\text { Milaria (biang } \\
\text { keringat) }\end{array}$ \\
\hline B008 & Intertrigo \\
\hline
\end{tabular}

\section{Data Gejala Penyakit}

Berikut ini merupakan data-data gejala dari setiap penyakit yang di dapat dari hasil wawancara langsung dengan pakar yang memiliki kompetensi dibidangnya.

Tabel 4.2 Gejala penyakit penyakit kulit pada anak

\begin{tabular}{|c|c|}
\hline $\begin{array}{c}\text { Kode } \\
\text { gejala }\end{array}$ & Gejala \\
\hline A01 & demam tinggi \\
\hline
\end{tabular}

\begin{tabular}{|c|c|}
\hline $\mathrm{A} 02$ & $\begin{array}{l}\text { Anak tetap sadar } \\
\text { dan aktif }\end{array}$ \\
\hline A03 & $\begin{array}{l}\text { pembengkakan } \\
\text { dikelenjar getah } \\
\text { bening pada bagian } \\
\text { leher, kepala, atau } \\
\text { telinga. }\end{array}$ \\
\hline A04 & $\begin{array}{l}\text { Adanya kemerahan } \\
\text { dikulit }\end{array}$ \\
\hline A05 & Tidak gatal \\
\hline A06 & Demam biasa \\
\hline A07 & $\begin{array}{l}\text { gangguan } \\
\text { pernapasan }\end{array}$ \\
\hline A08 & Muncul ruam dipipi \\
\hline A09 & $\begin{array}{l}\text { Ruam menyebar ke } \\
\text { seluruh bagian } \\
\text { tubuh }\end{array}$ \\
\hline A10 & Bintik-bintik lepuh \\
\hline A11 & $\begin{array}{l}\text { Bintik-bintik cepat } \\
\text { pecah }\end{array}$ \\
\hline A12 & $\begin{array}{l}\text { meninggalkan } \\
\text { keropeng }\end{array}$ \\
\hline A13 & $\begin{array}{l}\text { Bintik-bintik berisi } \\
\text { nanah }\end{array}$ \\
\hline A14 & $\begin{array}{l}\text { Bintik-bintik } \\
\text { mudah pecah }\end{array}$ \\
\hline A15 & $\begin{array}{l}\text { Muncul ruam } \\
\text { sekitar tubuh }\end{array}$ \\
\hline A16 & $\begin{array}{l}\text { suhu tubuh } \\
\text { meningkat }\end{array}$ \\
\hline A17 & $\begin{array}{l}\text { Bintik-bintik berisis } \\
\text { air }\end{array}$ \\
\hline A18 & $\begin{array}{l}\text { mengering dan } \\
\text { mengelupas }\end{array}$ \\
\hline A19 & flu berat \\
\hline A20 & batuk keras \\
\hline A21 & mata berair \\
\hline A22 & anak gelisah \\
\hline A23 & $\begin{array}{l}\text { sulit melihat cahaya } \\
\text { terang }\end{array}$ \\
\hline A24 & Gatal \\
\hline A25 & Pedih / perih \\
\hline A26 & Lecet \\
\hline A27 & Keluarnya cairan \\
\hline
\end{tabular}


ISSN 2338-1523

E-ISSN 2541-576X

Volume 6 No. 2

Desember 2018

\section{Analisa Proses}

Dalam tahap analisa proses ini dilakukan dengan menggunakan metode Backward Chaining merupakan proses untuk menghasilkan informasi dari fakta yang diketahui. Proses penelusuran menggunakan metode backward chaining yaitu metode inferensi yang bekerja mundur ke arah kondisi awal. Proses diawali dari Goal (yang berada dibagian THEN dari rule IF-THEN), kemudian pencarian mulai dijalankan untuk mencocokkan apakah fakta-fakta yang ada cocok dengan premis-premis dibagian IF.

\section{Proses Rule Dari Penyakit}

Proses rule didapatkan mengacu dari pohon pelacakan yang telah di buat, terdapatlah beberapa rule untuk pengetahuan mengenai gangguan atau masalah yang terjadi pada penyakit kulit pada anak, proses rule tersebut adalah sebagai berikut :

Diket R1 : IF A01 and A02 THEN A03

R2 : IF A03 THEN A04

R3 : IF A04 THEN A05

R4 : IF A03 and A04 and A05 THEN B01

R5 : IF A06 THEN A07

R6 : IF A07 and A08 THEN A09

R7 : IF A07 and A09 THEN B02

R8 : IF A04 and A10 THEN A11

R9 : IF A11 THEN A12

R10 : IF A11 and A12 THEN B03

R11 : IF A04 and A06 THEN A13

R12 : IF A13 THEN A14

R13 : IF A13 and A14 THEN B04

R14 : IF A15 THEN A16

R15 : IF A16 THEN A17

R16 : IF A16 and 17 THEN A18

R17 : IF A16 and A17 and A18 THEN

B05

R18 : IF A19 and A20 THEN A21
R19 : IF A21 THEN A22

R20 : IF A22 and A23 THEN A15

R21 : IF A15 THEN A05

$\mathrm{R} 22$ : IF $\mathrm{A} 21$ and $\mathrm{A} 22$ and $\mathrm{A} 15$ and $\mathrm{A} 05$

THEN B06

R23 : IF A24 and A25 THEN A04

R24 : IF A04 THEN A12

R25 : IF A04 and A12 THEN B07

R26 : IF A25 and A04 THEN A26

R27 : IF A26 THEN A27

R28 : IF A26 and A27 THEN B08

Tabel : 4.3 Proses Rule

Penyakit penyakit kulit pada anak

\begin{tabular}{|c|c|}
\hline Rule 1 & $\begin{array}{l}\text { IF demam tinggi } \\
\text { AND Anak tetap sadar } \\
\text { dan aktif } \\
\text { THEN pembengkakan } \\
\text { dikelenjar getah bening } \\
\text { pada bagian leher, kepala, } \\
\text { atau telinga }\end{array}$ \\
\hline Rule 2 & $\begin{array}{l}\text { IF pembengkakan } \\
\text { dikelenjar getah bening } \\
\text { pada bagian leher, kepala, } \\
\text { atau telinga. } \\
\text { THEN Adanya } \\
\text { kemerahan dikulit }\end{array}$ \\
\hline Rule 3 & $\begin{array}{l}\text { IF Adanya kemerahan } \\
\text { dikulit } \\
\text { THEN Tidak gatal }\end{array}$ \\
\hline Rule 4 & $\begin{array}{l}\text { IF pembengkakan } \\
\text { dikelenjar getah bening } \\
\text { pada bagian leher, kepala, } \\
\text { atau telinga. } \\
\text { AND Adanya kemerahan } \\
\text { dikulit } \\
\text { AND Tidak gatal } \\
\text { THEN Roseola infantum }\end{array}$ \\
\hline Rule 5 & $\begin{array}{l}\text { IF Demam biasa } \\
\text { THEN gangguan } \\
\text { pernapasan }\end{array}$ \\
\hline Rule 6 & $\begin{array}{l}\text { IF gangguan pernapasan } \\
\text { AND Muncul ruam dipipi } \\
\text { THEN Ruam menyebar } \\
\text { ke seluruh bagian tubuh }\end{array}$ \\
\hline Rule 7 & IF gangguan pernapasan \\
\hline
\end{tabular}

JURSIMA

Jurnal Sistem Informasi dan Manajemen https://ejournal.stmikgici.ac.id/

STMIK GICI 
ISSN 2338-1523

E-ISSN 2541-576X

Volume 6 No. 2

Desember 2018

\begin{tabular}{|c|c|}
\hline & $\begin{array}{l}\text { AND Ruam menyebar ke } \\
\text { seluruh bagian tubuh } \\
\text { THEN Parvoviru B19 } \\
\text { (sindrom pipi merah) }\end{array}$ \\
\hline Rule8 & $\begin{array}{l}\text { IF Adanya kemerahan } \\
\text { dikulit } \\
\text { AND Bintik-bintik lepuh } \\
\text { THEN Bintik-bintik cepat } \\
\text { pecah }\end{array}$ \\
\hline Rule9 & $\begin{array}{l}\text { IF Bintik-bintik cepat } \\
\text { pecah } \\
\text { THEN meninggalkan } \\
\text { keropeng }\end{array}$ \\
\hline Rule10 & $\begin{array}{l}\text { IF Bintik-bintik cepat } \\
\text { pecah } \\
\text { AND meninggalkan } \\
\text { keropeng } \\
\text { THEN Impetigo } \\
\text { krustosa(cacar madu) }\end{array}$ \\
\hline Rule11 & $\begin{array}{l}\text { IF Adanya kemerahan } \\
\text { dikulit } \\
\text { AND Demam biasa } \\
\text { THEN Bintik-bintik berisi } \\
\text { nanah }\end{array}$ \\
\hline Rule12 & $\begin{array}{l}\text { IF Bintik-bintik berisi } \\
\text { nanah } \\
\text { THEN Bintik-bintik } \\
\text { mudah pecah }\end{array}$ \\
\hline Rule13 & $\begin{array}{l}\text { IF Bintik-bintik berisi } \\
\text { nanah } \\
\text { AND Bintik-bintik mudah } \\
\text { pecah } \\
\text { THEN Impetigo bulosa } \\
\text { (cacar api) }\end{array}$ \\
\hline Rule14 & $\begin{array}{l}\text { IF Muncul ruam sekitar } \\
\text { tubuh } \\
\text { THEN Suhu tubuh } \\
\text { meningkat }\end{array}$ \\
\hline Rule15 & $\begin{array}{l}\text { IF Suhu tubuh meningkat } \\
\text { THEN Bintik-bintik } \\
\text { berisis air }\end{array}$ \\
\hline Rule16 & $\begin{array}{l}\text { IF Suhu tubuh meningkat } \\
\text { AND Bintik-bintik berisi } \\
\text { air }\end{array}$ \\
\hline
\end{tabular}

\begin{tabular}{|c|c|}
\hline & $\begin{array}{l}\text { THEN mengering dan } \\
\text { mengelupas }\end{array}$ \\
\hline Rule17 & $\begin{array}{l}\text { IF Suhu tubuh meningkat } \\
\text { AND Bintik-bintik berisi } \\
\text { air } \\
\text { AND mengering dan } \\
\text { mengelupas } \\
\text { THEN Cacar air }\end{array}$ \\
\hline Rule18 & $\begin{array}{l}\text { IF flu berat } \\
\text { AND Batuk berat } \\
\text { THEN mata berair }\end{array}$ \\
\hline Rule19 & $\begin{array}{l}\text { IF mata berair } \\
\text { THEN Anak gelisah }\end{array}$ \\
\hline Rule 20 & $\begin{array}{l}\text { IF Anak gelisah } \\
\text { AND sulit melihat cahaya } \\
\text { terang } \\
\text { THEN Muncul ruam } \\
\text { sekitar tubuh }\end{array}$ \\
\hline Rule 21 & $\begin{array}{l}\text { IF Muncul ruam sekitar } \\
\text { tubuh } \\
\text { THEN Tidak gatal }\end{array}$ \\
\hline Rule 22 & $\begin{array}{l}\text { IF mata berair } \\
\text { AND Anak gelisah } \\
\text { AND Muncul ruam } \\
\text { sekitar tubuh } \\
\text { AND Tidak gatal } \\
\text { THEN Rubeola (campak } \\
9 \text { hari) }\end{array}$ \\
\hline Rule 23 & $\begin{array}{l}\text { IF Gatal } \\
\text { AND Pedih / perih } \\
\text { THEN Adanya } \\
\text { kemerahan dikulit }\end{array}$ \\
\hline Rule 24 & $\begin{array}{l}\text { IF Adanya kemerahan } \\
\text { dikulit } \\
\text { THEN meninggalkan } \\
\text { keropeng }\end{array}$ \\
\hline Rule 25 & $\begin{array}{l}\text { IF Adanya kemerahan } \\
\text { dikulit } \\
\text { AND meninggalkan } \\
\text { keropeng } \\
\text { THEN Milaria (biang } \\
\text { keringat) }\end{array}$ \\
\hline Rule 26 & $\begin{array}{l}\text { IF Perih/pedih } \\
\text { AND meninggalkan } \\
\text { keropeng }\end{array}$ \\
\hline
\end{tabular}


ISSN 2338-1523

E-ISSN 2541-576X

Volume 6 No. 2

Desember 2018

\begin{tabular}{|l|l|}
\hline & THEN Lecet \\
\hline Rule 27 & $\begin{array}{l}\text { IF Lecet } \\
\text { THEN Keluarnya cairan }\end{array}$ \\
\hline Rule 28 & $\begin{array}{l}\text { IF Lecet } \\
\text { AND Keluarnya cairan } \\
\text { THEN Intertrigo }\end{array}$ \\
\hline
\end{tabular}

\section{Hasil}

Hasil dari perancangan website sistem pakar ini dapat dilihat apabila aplikasi ini dijalankan pada sebuah komputer dengan web browser, seperti operamini, mozila, google chrome dan internet explorer. Pengguna website sistem pakar ini dapat mencari informasi dan melakukan konsultasi pada suatu jenis penyakit kulit pada anak secara komputerisasi maupun via online. Pengguna dapat memilih beberapa menu form yang tersedia dan ditampilkan pada form utama yang terdapat dalam website. Untuk lebih jelasnya dapat dilihat pada langkahlangkah menjalankan website berikut ini

\section{Halaman Home}

Halaman home merupakan halaman utama sekaligus halaman pembuka dari website sistem pakar yang dibuat untuk menjalankan website lebih lanjut. Pada halaman ini juga terdapat fasilitas login yang dapat diakses oleh pengguna, akan tetapi pengguna terlebih dahulu memastikan telah menjadi member sebelumnya.

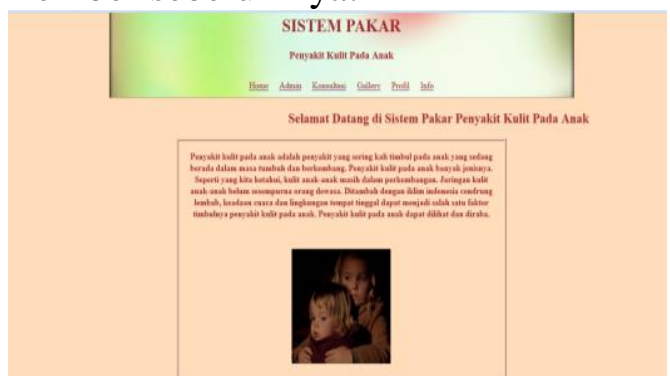

Gambar 4.1 Halaman Home

\section{Halaman Pendaftaran}

Pengguna harus melakukan pendaftaran terlebih dahulu guna mendapatkan username dan password pengguna yang digunkan untuk masuk kedalam halaman konsultasi, baru kemudian pengguna dapat melakukan konsultasi menggunakan website sistem pakar ini. Adapun tampilan halaman pendaftaran dapat kita lihat pada Gambar 4.2 berikut ini :

\section{Gambar 4.2 Halaman Pendaftaran}

\section{Halaman Login}

Tampilan halaman login user member merupakan halaman yang dirancang sedemikan rupa pada website sistem pakar ini. Dimana pengguna harus melakukan login agar bisa melanjutkan ke halaman konsultasi atau sesi pemilihan gejala-gejala oleh pengguna. Adapun tampilan halaman login dapat kita lihat pada Gambar 4.3berikut ini :

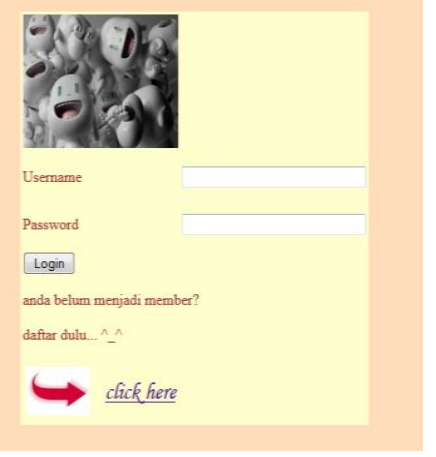

Gambar 4.3 Halaman Login

\section{Halaman Hasil Diagnosa}


ISSN 2338-1523

E-ISSN 2541-576X

Volume 6 No. 2

Desember 2018

Merupakan halaman yang menampilkan hasil dari diagnosa berdasarkan jenis, nilai pridiksi dan gejala-gejala penyakit hipertensi yang telah dipilih oleh pengguna. Adapun tampilan halaman hasil diagnosa dapat kita lihat pada Gambar 4.6 berikut ini :

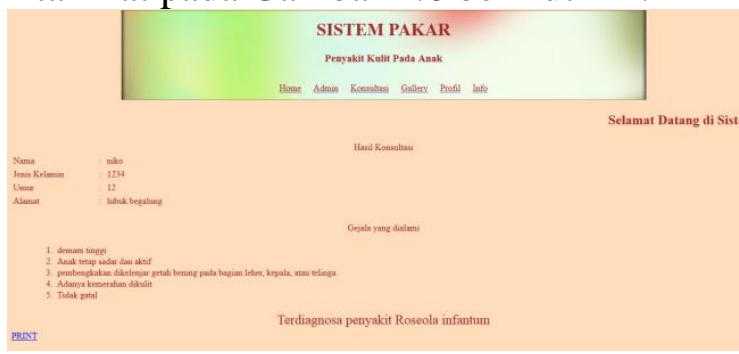

Gambar 4.5 Halaman Hasil Diagnosa

\section{KESIMPULAN}

Dari penulisan tugas akhir ini mulai dari tahapan analisa permasalahan yang ada hingga pengujian sistem yang baru dirancang maka dapat diambil beberapa kesimpulan, yaitu:

1. Dengan pembangunan aplikasi sistem pakar untuk penyakit kulit pada anak akan membantu pasien dalam mendiagnosa penyakit kulit pada anak.

2. Berdasarkan hasil uji, sistem pakar ini dapat memberikan informasi tentang gejala penyakit kulit pada anak kepada pasien.

3. Berdasarkan penelitian, maka diperoleh 8 jenis gangguan, 27 gejala dan 28 aturan (rule).

\section{KATA TRIMAKSIH}

Trimakasih kepada dosen pembimbing saya yang telah membina saya sewaktu kuliah dulu, dan trimakasih kepada teman teman yang telah mensuport saya, dan tidak lupa saya trimakasih kepada allah atas segala rahmat dan karunia yang telah di berikan kepada saya, dan trimakasih kepada kepada orang tua saya ucapkan karna telah mendidik saya dari lahir hingga saat ini.

\section{DAFTAR PUSTAKA}

Deni Sutaji. (2012). Sistem Inventory Mini Market Dengan PHP \& JQUERY. Lokomedia : Yogyakarta

Ema Utami, Sukrisno. (2005). 10 Langkah Belajar Logika dan Algoritma, Menggunakan

Bahasa $C$ dan $C++d i$ GNU/LINUX. Andi : Yogyakarta

Loka Dwiartara. Menyelam dan Menaklukkan Samudra PHP. Ilmu Website

Master Dukom. (2011). Menjadi Master Website Gratis Dalam Hitungan Menit. Dunia Komputer : Bekasi

Munawar. (2005). Permodelan Visual dengan UML. Graha Ilmu : Yogyakarta

Rosa A.S, \& M. Shallahudin. (2011). Rekayasa Perangkat Lunak. Modula : Bandung

T. Sutojo, dkk. (2011). Kecerdasan Buatan. Andi : Yogyakarta

Wahana Komputer. (2005). Menjadi Seorang Desainer Web. Andi : Yogyakarta
JURSIMA

Jurnal Sistem Informasi dan Manajemen https://ejournal.stmikgici.ac.id/

STMIK GICI 